\title{
Therapeutic effects of acupuncture with MOK, a polyherbal medicine, on PTU-induced hypothyroidism in rats
}

\author{
JI HYE HWANG ${ }^{1}$, HYO WON JUNG ${ }^{2}$, SEOK YONG KANG ${ }^{2}$, AN NA KANG $^{2}$, JUN NAN MA ${ }^{2}$, \\ XIANG LONG MENG ${ }^{2}$, MIN SUB HWANG ${ }^{3}$ and YONG-KI PARK ${ }^{2}$

\begin{abstract}
${ }^{1}$ Department of Acupuncture and Moxibustion Medicine, College of Korean Medicine, Gachon University, Seongnam, Gyeonggi 13120; Departments of ${ }^{2}$ Herbology and ${ }^{3}$ Acupuncture and Moxibustion Medicine, College of Korean Medicine, Dongguk University, Gyeongju, Gyeongbuk 38066, Republic of Korea
\end{abstract}

Received August 8, 2017; Accepted May 4, 2018

DOI: $10.3892 / \mathrm{etm} .2018 .6190$

\begin{abstract}
Acupuncture with MOK, a polyherbal medicine (MOK pharmacopuncture), has been used for the treatment of thyroid syndromes including hypothyroidism and hyperthyroidism in traditional Korean medicine. The present study investigated the effect of MOK pharmacopuncture on hypothyroidism and the mechanism underlying its antioxidation and immune regulation effects. Hypothyroidism was induced in Sprague-Dawley rats by subcutaneous injection of Propylthiouracil (PTU; $10 \mathrm{mg} / \mathrm{kg}$ ) once daily for 4 weeks. MOK was administered by acupuncture on the acupoints around the thyroid gland of PTU-induced hypothyroidism rats once daily for 2 weeks following hypothyroidism induction. Administration of MOK pharmacopuncture significantly increased the PTU-induced decrease in body temperature of hypothyroidism rats. The weights of the spleen were also significantly decreased in hyperthyroidism rats following MOK pharmacopuncture. MOK pharmacopuncture significantly decreased the thyroid stimulating hormone level and increased the T3 and T4 levels in hypothyroidism rats. Administration of MOK pharmacopuncture significantly increased the glucose levels and decreased the levels of triglycerides, total cholesterol, low-density lipoprotein-cholesterol, and alanine transaminase in the sera of hypothyroidism rats. The expression of transient receptor potential cation channel subfamily $\mathrm{V}$ member 1 was increased in dorsal root ganglion and brain tissues by administration of MOK pharmacopuncture, and glutathione levels and the expression of superoxide dismutase 1 and catalase were increased in the liver and brain tissues. Administration of MOK pharmacopuncture significantly inhibited interferon $\gamma$ expression and increased the expression
\end{abstract}

Correspondence to: Dr Yong-Ki Park, Department of Herbology, College of Korean Medicine, Dongguk University, 123 Dongdae-ro, Gyeongju, Gyeongbuk 38066, Republic of Korea

E-mail: yongki@dongguk.ac.kr

Key words: acupuncture, hypothyroidism, MOK, pharmacopuncture, TRPV1 channel, antioxidant, Th1/Th2 balance of interleukin (IL)-4, IL-10, and Forkhead Box P3 in the spleen tissues of hypothyroidism rats. In histological analysis, the administration of MOK pharmacopuncture improved the pathological features in the thyroid glands of hypothyroidism rats. The results suggested that the administration of pharmacopuncture may ameliorate the pathological progression of hypothyroidism by multiple actions, including normalization of the hypothyroidism-induced thyroid hormone imbalance, stimulation of the antioxidant defense system, and regulation of the T helper (Th)1/Th2 imbalance. Therefore, MOK extract may be used for the treatment of hypothyroidism in Korean clinics as a useful pharmacopuncture medicine.

\section{Introduction}

Hypothyroidism, also known as underactive thyroid disease, is a typical endocrine disorder of the thyroid gland that is caused due to inadequate quantities of thyroid hormones such as thyroxine (T4) and triiodothyronine (T3). The common symptoms of hypothyroidism are tiredness, weight gain, constipation, aches, dry skin, dry hair and feeling cold, accompanied by a low metabolism. The most common cause of hypothyroidism is Hashimoto's thyroiditis, an autoimmune disorder. The thyroid gland controls the body's energy metabolism, which affects the body temperature, heartbeat, and calorie burning. The thyroid hormones have wide effects on homeostasis and play an important role in the balance of the cardiovascular system. Thus, patients with hypothyroidism have an increased risk of cardiovascular abnormalities such as accelerated atherosclerosis (1-3). For hypothyroidism treatment, a synthetic thyroid hormone T4, L-Thyroxine (LT4) has been prescribed as a first treatment regimen, but thyroid replacement hormones are usually well tolerated. Symptoms that occur during treatment are often due to toxic, elevated levels of thyroid hormones and resulting the symptoms from hyperthyroidism.

Traditional medicines, including traditional Chinese medicine (TCM) and traditional Korean medicine (TKM), regard the treatment of both hyperthyroidism and hypothyroidism as concepts of Yin/Yang imbalance. When treating either condition, acupuncture, herbal medicine, and dietary therapy are typically employed to rebalance an individual's imbalance of 
Yin and Yang. According to the World Health Organization (WHO), acupuncture can be used to treat thyroid diseases, and several studies have suggested that acupuncture can be beneficial in treating hypothyroidism. Although acupuncture is popularly applied in many countries for the treatment of various disorders, the scientific evidence of safety and efficacy is still an important issue that deserves close attention. Pharmacopuncture therapy, a new form of acupuncture treatment in TKM, is a stimulating method on acupoints with the injection of herbal medicines that are frequently used for the regulation of immune balance in clinical settings $(4,5)$. MOK is a polyherbal medicine consisting of 10 herbs and is commonly used for pharmacopuncture treatment of thyroid syndromes such as hypothyroidism, hyperthyroidism, and heart diseases in Korean clinics $(5,6)$. MOK has been reported to exhibit anti-inflammatory activity, antioxidant effects $(7,8)$, and modulation of Th1/Th2 immune response (9) in in vitro studies and exert clinical effects on Hwa-Byung (6) which is known to cause of thyroid syndromes $(5,10)$. However, it has still little scientific evidence.

Therefore, in this study, we investigated the effects of acupuncture with MOK (MOK pharmacopuncture) on Propylthiouracil (PTU)-induced hypothyroidism in rats and studies the mechanism underlying the anti-hypothyroidism effects of MOK pharmacopuncture, with a focus on antioxidation and Th1/Th2 immune regulation.

\section{Materials and methods}

Preparation of MOK extract. MOK consists of 10 herbs (Table I). All raw materials of MOK were purchased from herbal materials company (Jayeondameun, Yangju, Korea), and authenticated by the Korean Food and Drug Administration (KFDA). Their voucher specimens (KIPA-MOK01 10) were deposited at the Korea Immuno-Pharmacopuncture Association (KIPA, Seoul, Korea). MOK extract was manufactured under a good manufacturing practice (GMP)-compliant facility (7). Therefore, MOK was extracted with dried ten herbs $(106.2 \mathrm{~g})$ in distilled water $(1 \mathrm{~L})$, mixed with alcohol in a ratio of $1: 1(\mathrm{v} / \mathrm{v})$, filtered through a two-layer mesh, and adjusted $\mathrm{pH} 7.2$ to 7.6 with $\mathrm{NaOH}$ for making a $0.9 \%$ isotonic solution. This solution was concentrated under vacuum pressure, and freeze-dried (the yield of $53.1 \mathrm{mg} / \mathrm{ml}$ ). MOK was stored at $4^{\circ} \mathrm{C}$ until use, at which time it was dissolved in sterilized water.

Experimental animals. Male Sprague-Dawley (SD) rats, aged five weeks, were purchased from SLC, Inc. (Shizuoka, Japan). All animals received food and water ad libitum and were housed under standard laboratory conditions at an ambient temperature of $22 \pm 3{ }^{\circ} \mathrm{C}$ with humidity of $60 \pm 5 \%$ under a daily 12/12 h light/dark schedule. All animals were handled according to the Animal Welfare Guidelines issued by the Korean National Institute of Health and the Korean Academy of Medical Sciences for the care and use of laboratory animals. This study was conducted with the approval of the Institutional Animal Care and Use Commitee of Dongguk University (IACUC; No. 130387).

Induction of hypothyroidism. For the induction of hypothyroidism, we used the method based on previous reports (11-13) with minor modification (Fig. 1). PTU (Sigma-Aldrich; Merck $\mathrm{KGaA}$, Darmstadt, Germany) at $10 \mathrm{mg} / \mathrm{kg} /$ body weight (BW) was dissolved in $0.3 \mathrm{ml}$ saline, and the rats were given a daily subcutaneous injection of PTU into the dorsal neck for 28 days. In normal rats, saline was subcutaneously injected at a volume of $0.3 \mathrm{ml} / \mathrm{animal}$, instead of PTU. Two weeks later, MOK pharmacopuncture at 0.3 and $1.5 \mathrm{mg} / \mathrm{kg}$ was administered subcutaneously into the anterior neck near the thyroid gland at a volume of $0.15 \mathrm{ml} / \mathrm{animal}$; the compound was dissolved in saline and administered once daily from day 15 to day 28 after the induction of hypothyroidism. The rats in the control group were injected with an equal volume of saline by the same method. LT4 at $0.5 \mathrm{mg} / \mathrm{kg}$ (Sigma-Aldrich; Merck KGaA) was used as a reference drug. The rats were randomly divided into four groups of five animals each: normal group (Normal), PTU-induced hypothyroidism control group (PTU+Vehicle), MOK pharmacopuncture 0.3 ml-treated group (PTU+Low MOK), MOK pharmacopuncture $1.5 \mathrm{ml}$-treated group (PTU+High MOK), and LT-administered group (PTU+LT4).

Measurement of $B W$ and food and water intake. All animals were observed daily for clinical signs for 4 weeks from the first injection day. The BW and food consumption of each rat were measured at the initiation of treatment and once a week during the treatment period. The amounts of food and water intake were averaged every week during the treatment period.

Measurement of body temperature. Rectal temperature was measured once a week in all animals using a Thermalert TH-8 (Physitemp Instruments, Clifton, NJ, USA) monitor with a (RET-2) rectal probe attached to the thermocouple. White petrolatum (Gallipot, St. Paul, MN, USA) was applied to the probe before insertion. The probe was inserted $3 \mathrm{~cm}$ into the rectum while the rat was gently restrained. A steady readout was obtained within $30 \mathrm{~s}$ of probe insertion.

Serological analysis. Blood samples were collected by cardiac puncture under isoflurane (1.5 to $3.0 \%$ ) anesthesia, and the rats were sacrificed on day 36 after the primary immunization. Blood was clotted for $2 \mathrm{~h}$ at room temperature (RT) and centrifuged at $5,000 \mathrm{x}$ g for $10 \mathrm{~min}$ at $4^{\circ} \mathrm{C}$ to obtain serum.

The levels of thyroid-stimulating hormone (TSH), T3, and T4 were measured in the sera of rats using commercially available enzyme-linked immunosorbent assay (ELISA) kits according to the manufacturer's recommendations (Cusabio, Wuhan, China). The concentration of each hormone was calculated from the standard curve for each hormone in the ELISA kits. Serum aspartate transaminase (AST), alanine transaminase (ALT), total cholesterol, HDL-cholesterol, LDL-cholesterol, triglyceride (TG), and glucose levels were measured with an automated blood analyzer (FDC7000i; Fujifilm Corporation, Tokyo, Japan)) and an ELISA reader (ASYS Hitech GmbH, Eugendorf, Austria).

Histological analysis. On day 36, all rats were sacrificed by anesthesia after serum collection. Thyroid tissues were removed from the mice for histological examination. Thyroid tissues were fixed in $4 \%$ paraformaldehyde solution, decalcified with Calci-Clear Rapid (National Diagnostics, Atlanta, GA, USA), embedded in paraffin, and longitudinally cut into $5-\mu \mathrm{m}$ serial 
Table I. Constituents of MOK extract.

\begin{tabular}{lllll}
\hline $\begin{array}{l}\text { No. of } \\
\text { KIPA-MOK }\end{array}$ & \multicolumn{1}{c}{$\begin{array}{c}\text { Herbal name } \\
\text { (part of medicinal use) }\end{array}$} & \multicolumn{1}{c}{$\begin{array}{c}\text { Scientific name } \\
\text { Ratio (g) }\end{array}$} & Standard compounds \\
\hline 01 & Hominis Placenta (placenta) & Hominis placenta & 4 & Alanine, luecine \\
02 & Moschus (bear's gall) & Moschusberezovskii & 1 & Muscone \\
03 & FelUrsi (musk) & Ursusarctos & 0.6 & Ursodeoxycholic acid \\
04 & Calculus Bovis Cow bezoar (cow gallstone) & Bostaurus & 0.6 & Bilirubin \\
05 & Scutellariae Radix (root) & Scutellariabaicalensis & 20 & Baicalein \\
06 & Phellodendri Cortex (bark) & Phellodendronamurense & 20 & Berberinechloride \\
07 & PulsatillaKoreana (root) & Pulsatillakoreana & 20 & Anemonin, saponin \\
08 & SophoraeSubprostratae Radix (root) & Sophoratonkinensis & 20 & Oxymatrine \\
09 & Aucklandiae Radix (root) & Aucklandialappa & 10 & Dehydrocostus lactone \\
10 & Aquilariaagallocha (bark) & Aquilariaagallocha & 10 & Tannic acid \\
\hline
\end{tabular}

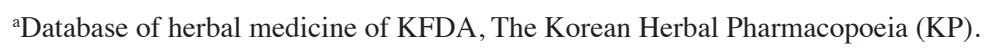

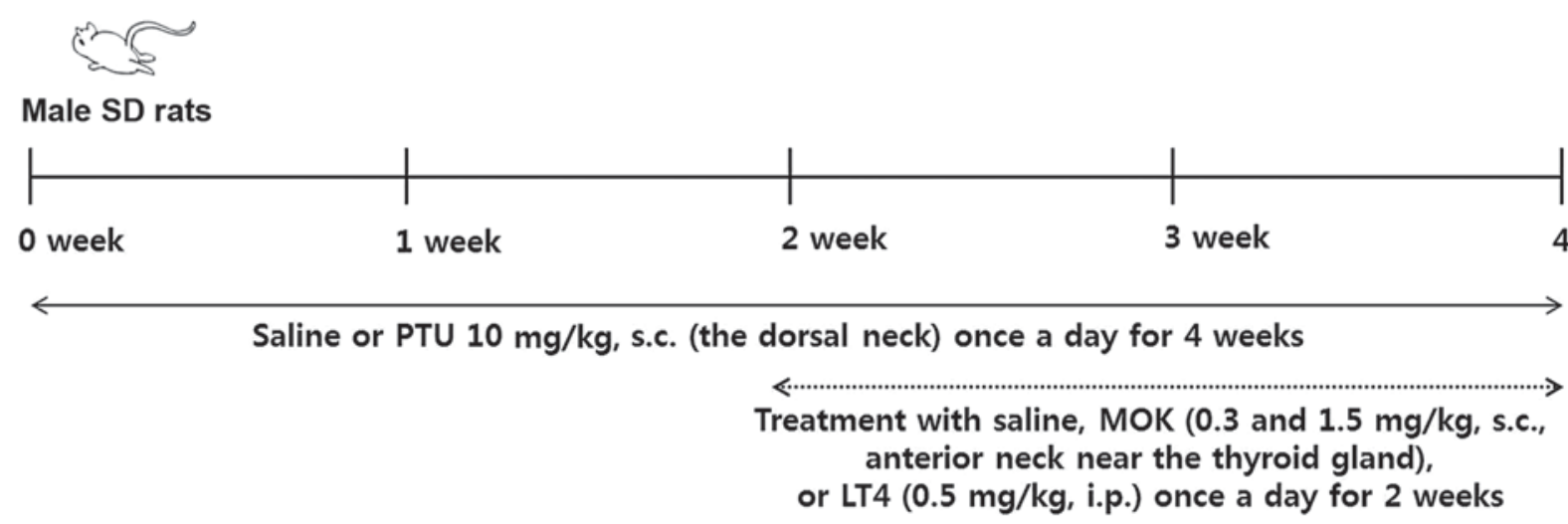

Figure 1. Experimental design and schedule of treatment in rat model of hypothyroidism.

sections. The sections were then stained with hematoxylin and eosin (H\&E) to assess morphological changes of the thyroid glands. To observe histopathological changes in more detail, the mean thyroid follicular sizes were calculated using ImageJ [National Institutes of Health (NIH), Bethesda, MD, USA].

Western blot analysis. To investigate the effects of MOK pharmacopuncture on the oxidation of liver, heart, and brain tissues, as well as expressions of the transient receptor potential cation channel subfamily V member 1 (TRPV1) protein in dorsal root ganglion (DRG) and brain tissues, we conducted western blot analysis. Briefly, livers, brains, and DRG tissues were harvested from each group, minced, and homogenized with an electric homogenizer in 5 volumes of extraction buffer (100 mM Tris, pH 7.4, $150 \mathrm{mM}$ sodium chloride $(\mathrm{NaCl}), 1 \mathrm{mM}$ ethylene glycol-bis ( $\beta$-aminoethyl ether)-N,N,N',N'-tetraacetic acid (EGTA), $1 \mathrm{mM}$ ethylenediamine tetraacetic acid (EDTA), $1 \%$ Triton $\mathrm{X}-100$, and $0.5 \%$ sodium deoxycholate). The tissue lysates were placed on a shaker at $4{ }^{\circ} \mathrm{C}$ for $1 \mathrm{~h}$ and centrifuged at $10,000 \mathrm{x} g$ for $5 \mathrm{~min}$. Protein concentrations were determined by the Bradford assay (Bio-Rad, Hemel Hempstead, UK). A total of $30 \mu \mathrm{g} / \mathrm{ml}$ of protein was separated on a 10 to $12 \%$ sodium dodecyl sulfate (SDS)-polyacrylamide gel and then transferred to a nitrocellulose membrane (EMD Millipore,
Billerica, MA, USA). Each membrane was incubated for $1 \mathrm{~h}$ with $5 \%$ skim milk in TBS-T buffer $(0.1 \mathrm{M}$ Tris- $\mathrm{HCl}, \mathrm{pH} 7.4$, $0.9 \% \mathrm{NaCl}, 0.1 \%$ Tween-20) to block non-specific binding and incubated with primary anti-superoxide dismutase 2 (SOD2), catalase (CAT) and TRPV1 antibodies (Cell Signaling Technology, Inc., Danvers, MA, USA), and anti- $\beta$-actin antibody (Sigma-Aldrich; Merck KGaA) antibodies. The membranes were incubated with peroxidase-conjugated affinity goat anti-rabbit IgG (Santa Cruz Biotechnology, Inc., Dallas, TX, USA). Each protein was detected using a chemiluminescence detection system according to the manufacturer's instructions (ECL; Amersham, Berkshire, UK). The band intensity was quantified by densitometric analysis using ImageJ software (NIH).

Measurement of total glutathione (GSH) levels. The contents of total glutathione was measured in the sera of all animals using the GSH/glutathione disulfide (GSSG) assaykit (Cell Biolabs, Inc., San Diego, CA, USA) based on the presence of GSH reductase that reduces GSSG to GSH in the presence of nicotinamide adenine dinucleotide phosphate-oxidase (NADPH). Subsequently, the chromogen reacts with the thiol group of GSH to produce a colored compound that absorbs at $405 \mathrm{~nm}$ ). Data were expressed as $\mu \mathrm{M}$ of GSH per gram of liver tissue. 

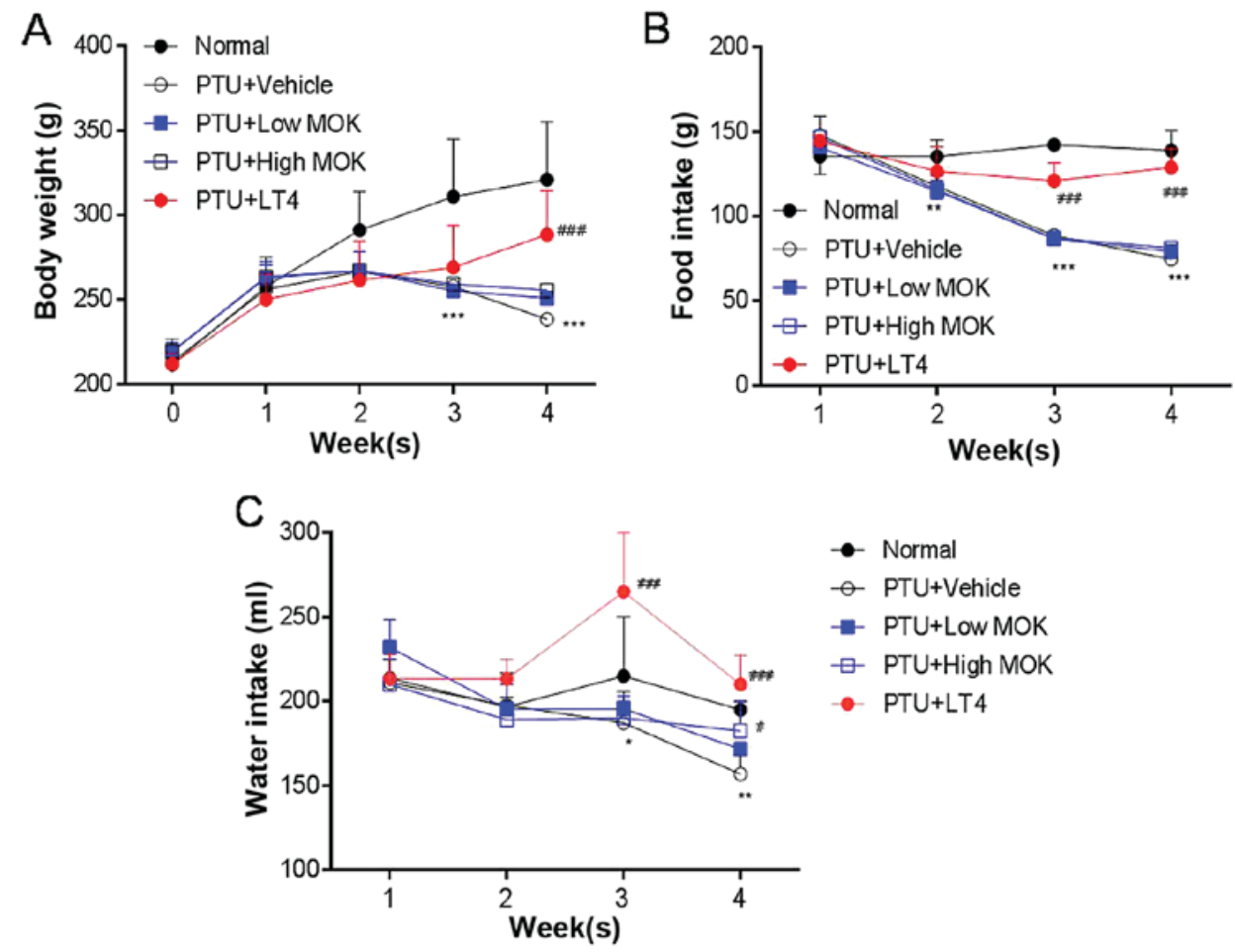

Figure 2. Effects of MOK pharmacopuncture on the changes of physiological parameters in PTU-induced hypothyroidism rats. MOK pharmacopuncture was subcutaneously administered once daily for 2 weeks, and the (A) body weight (B) food and (C) water intake were measured once a week. Data are presented

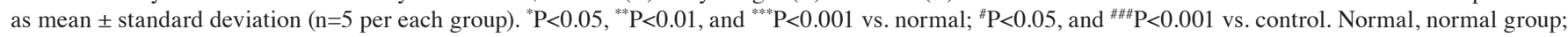
PTU+Vehicle, control group; PTU+Low MOK, MOK $0.3 \mathrm{ml} / \mathrm{kg}$-treated group in control; PTU+High MOK, MOK $1.5 \mathrm{mg} / \mathrm{kg}$-treated group in control; and PTU+LT4, L-Thyroxine $0.5 \mathrm{mg} / \mathrm{kg}$-treated group as a reference drug.

Isolation of splenocytes. Briefly, spleen tissues were rapidly harvested from SD rats, minced, and passed through stainless steel mesh to obtain single-cell suspension. Spleen cells were suspended with $1 \mathrm{X}$ phosphate-buffered saline (PBS), centrifuged at 5,000 x g for $5 \mathrm{~min}$, and cell pellets were harvested. Erythrocytes were removed using red blood cell lysis buffer (Sigma-Aldrich; Merck KGaA).

Reverse transcription-polymerase chain reaction ( $R T-P C R)$ assay. Total RNA was isolated from splenocytes from the rats using TRIzol reagent, and cDNA synthesis from total RNA with a mixture including oligo-dT primer, 5X RT buffer (Promega Corporation, Madison, WI, USA), 0.5 mM dNTP, $3 \mathrm{mM} \mathrm{MgCl}_{2}$, RNase inhibitor, and Improm- $\mathrm{II}^{\mathrm{TM}}$ reverse transcriptase (2U) was carried out at $25^{\circ} \mathrm{C}$ for $5 \mathrm{~min}$ and $42^{\circ} \mathrm{C}$ for $60 \mathrm{~min}$. The reaction was terminated at $70^{\circ} \mathrm{C}$ for $10 \mathrm{~min}$. PCR was carried out using specific primers for the target genes and PCR mixture [ $2 \mu \mathrm{l}$ cDNA, $4 \mu \mathrm{M} 5^{\prime}$ and $3^{\prime}$ primers, 10X buffer (10 mM Tris- $\mathrm{HCl}, \mathrm{pH} 8.3), 50 \mathrm{mM} \mathrm{KCl}, 0.1 \%$ Triton $\mathrm{X}-100$, $25 \mathrm{mM} \mathrm{MgCl}_{2}, 250 \mu \mathrm{M}$ dNTPs, and $1 \mathrm{U}$ Taq polymerase] under the following incubation conditions: $30 \mathrm{sec}$ denaturation at $94^{\circ} \mathrm{C}$, $30 \mathrm{sec}$ annealing at 58 to $60^{\circ} \mathrm{C}, 1 \mathrm{~min}$ extension, and $10 \mathrm{~min}$ final extension at the end of 30 cycles. The primer sequences were as follows: 5'-TCAACAACCCACAGGTCCAG-3' (sense), 5'-CTTCCTGAGGCTGGATTCCG-3' (anti-sense) for IFN- $\gamma$ (XM_006532446.3); 5'-AGATGGATGTGCCAAACGTCC TCA-3' (sense), 5'-AATATGCGAAGCACCTTGGAAGCC-3' (anti-sense) for IL-4 (NM_021283.2); 5'-GGACAACATACT GCTAACCGAC-3' (sense), 5'-TGGATCATTTCCGATAAG GCTTG-3' (anti-sense) for IL-10 (NM_010548.2); 5'-GGC
CCTTCTCCAGGACAGA-3' (sense), 5'-GCTGATCATGGC TGGGTTGT-3' (anti-sense) for Foxp3 (NM_001199348.1); and 5'-CTCGTGGAGTCTACTGGTGT-3' (sense), 5'-GTC ATCATACTTGGCAGGTT-3' (anti-sense) for glyceraldehyde 3-phosphate dehydrogenase (GAPDH, NM_001289726.1) as a control for PCR. Band intensity was quantified by automated densitometric analysis (ChemiDoc MP Imaging System; Bio-Rad Laboratories, Inc., Hercules, CA, USA).

Statistical analysis. GraphPad Prism (GraphPad Software, Inc., La Jolla, CA, USA) was used for statistical analysis. Data were expressed as mean \pm SEM (standard error of mean) of three separate experiments and were analyzed for statistical significance using ANOVA, followed by Tukey's test for multiple comparison. Null hypotheses of no difference were rejected for $\mathrm{P}<0.05$.

\section{Results}

Effect of MOK pharmacopuncture on physiological parameters in hypothyroidism rats. BWs were significantly decreased in PTU-induced hypothyroidism rats $(\mathrm{P}<0.05,0.001$ and 0.001 , respectively) from 2,3 , and 4 weeks after initial PTU treatment as compared with that in the normal group. MOK pharmacopuncture did not inhibit PTU-induced loss of BW (Fig. 2A); however, significant inhibition $(\mathrm{P}<0.001)$ of BW loss was observed in the LT4-treated group as a reference group from 2 weeks after initial treatment as compared with the PTU-control group. We also observed the changes in food and water intake for 4 weeks. Food/water consumption 

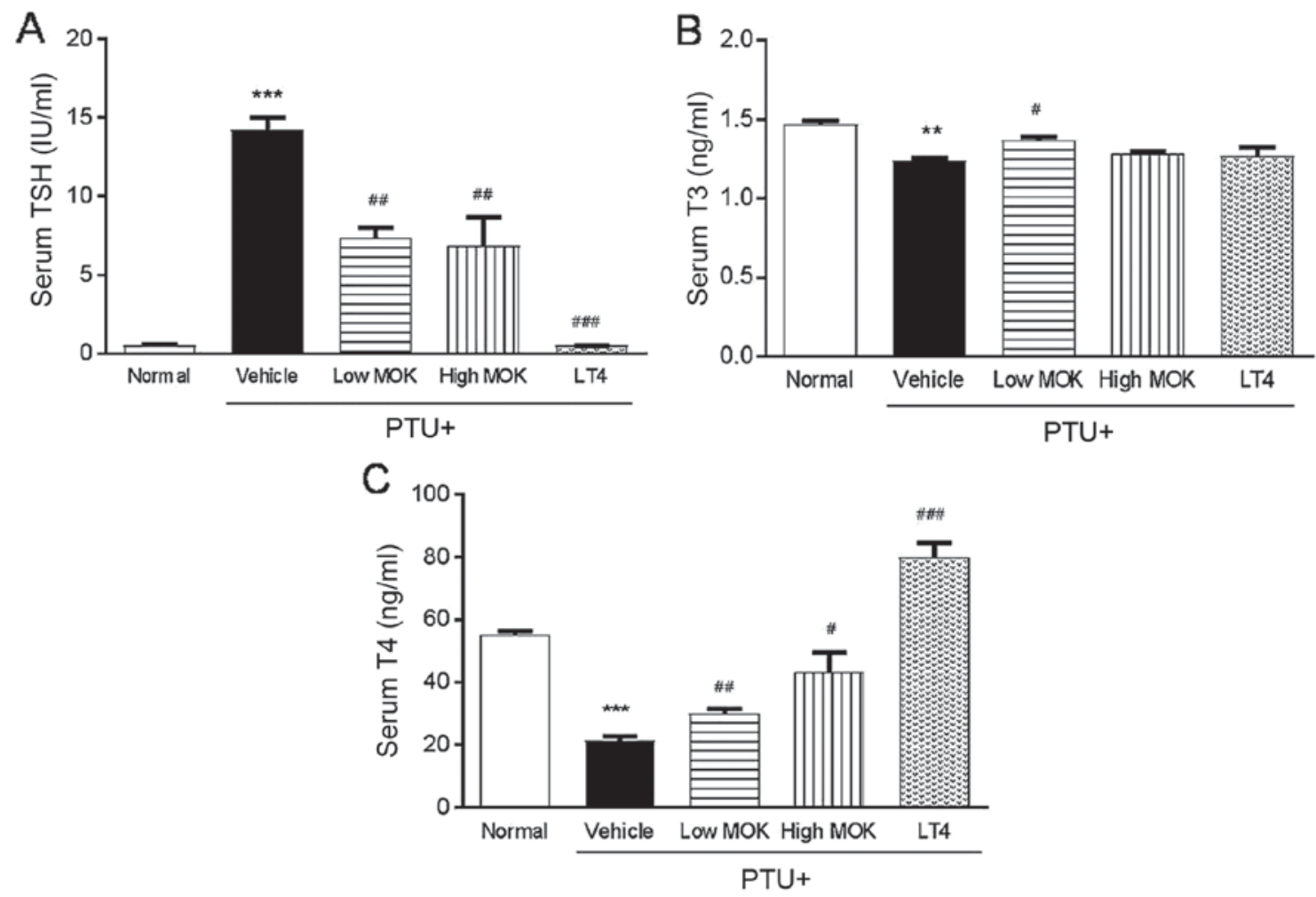

Figure 3. Effects of MOK pharmacopuncture on the levels of thyroid hormones in PTU-induced hypothyroidism rats. MOK pharmacopuncture was subcutaneously administered once daily for 2 weeks, and the levels of (A) TSH, (B) T3, and (C) T4 in the sera of rats were measured by ELISA, respectively. Data are presented as mean \pm standard deviation ( $\mathrm{n}=5$ per each group). ${ }^{* *} \mathrm{P}<0.01$, and ${ }^{* * * *} \mathrm{P}<0.001$ vs. normal; ${ }^{*} \mathrm{P}<0.05,{ }^{\# \#} \mathrm{P}<0.01$, and ${ }^{\# \# \#} \mathrm{P}<0.001$ vs. control. Normal, normal group; PTU+Vehicle, control group; PTU+Low MOK, MOK $0.3 \mathrm{ml} / \mathrm{kg}$-treated group in control; PTU+High MOK, MOK $1.5 \mathrm{mg} / \mathrm{kg}$-treated group in control; and PTU+LT4, L-Thyroxine $0.5 \mathrm{mg} / \mathrm{kg}$-treated group as a reference drug.

significantly decreased from 3 and 4 weeks after initial PTU treatment compared with that of the normal group. However, no significant differences in food (Fig. 2B) and water consumption (Fig. 2C) were found in the MOK pharmacopuncture at 0.3 and $1.5 \mathrm{mg} / \mathrm{kg}$ in PTU-induced hypothyroidism rats. LT4-treated group was also showed a significant increase in food and water consumption compared with the control group.

Effect of MOK pharmacopuncture on the levels of thyroid hormones in hypothyroidism rats. As shown in Fig. 3, a significant increase in serum TSH level $(\mathrm{P}<0.001)$ and decrease in serum T3 $(\mathrm{P}<0.01)$ and T4 $(\mathrm{P}<0.001)$ levels were detected in PTU-induced hypothyroidism rats compared with normal controls. MOK pharmacopuncture at 0.3 and $1.5 \mathrm{mg} / \mathrm{kg}$ in hypothyroidism rats significantly $(\mathrm{P}<0.01$, respectively) decreased serum TSH levels (Fig. 3A) and significantly $(\mathrm{P}<0.01$ and $\mathrm{P}<0.05)$ increased serum T4 levels (Fig. 3C). The LT4-treated group also showed a significant $(\mathrm{P}<0001)$ decrease in TSH levels $(\mathrm{P}<0.001)$ and a significant $(\mathrm{P}<0.001)$ increase in T4 levels $(\mathrm{P}<0.001)$ compared with the control group. In T3 levels, MOK pharmacopuncture at low concentration in hypothyroidism rats significantly $(\mathrm{P}<0.05)$ increased, but MOK pharmacopuncture at high concentration or LT4 treatment did not show a significant decrease (Fig. 3B).

Effect of MOK pharmacopuncture on serological parameters in hypothyroidism rats. In PTU-induced hypothyroidism rats, a significant decrease in serum glucose $(\mathrm{P}<0.001$, Fig. 4A) and TG $(\mathrm{P}<0.05$; Fig. 4B) levels and an increase in serum total cholesterol $(\mathrm{P}<0.001$; Fig. $4 \mathrm{C})$, LDL-cholesterol $(\mathrm{P}<0.001$, Fig. 4D), AST ( $\mathrm{P}<0.05$; Fig. 4E), and ALT ( $\mathrm{P}<0.01$; Fig. 4F) levels were observed compared with those of the normal group. The MOK pharmacopuncture group at high concentration showed significantly increased glucose levels $(\mathrm{P}<0.05)$ and decreased levels of total cholesterol $(\mathrm{P}<0.01)$, LDL-cholesterol $(\mathrm{P}<0.001)$, and AST $(\mathrm{P}<0.01)$ compared with those of the control group. In the LT4-treated group, a significant increase in glucose $(\mathrm{P}<0.01)$ and $\mathrm{TG}(\mathrm{P}<0.05)$ levels and a decrease in total cholesterol $(\mathrm{P}<0.001)$, and LDL-cholesterol $(\mathrm{P}<0.001)$ were detected compared with those of the control group, but did not change the levels of AST and ALT.

Effects of MOK pharmacopuncture on histopathological changes in the thyroid gland of hypothyroidism rats. PTU treatment induced the destruction of the thyroid gland with marked and noticeable hypertrophic changes related hyperplasia of follicular cells and decrease in follicular diameters and colloids. In PTU-induced hypothyroidism rats, increase in total thyroid gland thickness and decrease in mean follicular size were also observed compared with those of the normal group (Fig. 5). However, MOK pharmacopuncture at 0.3 and $1.5 \mathrm{mg} / \mathrm{kg}$ or LT4 treatment was shown to decrease the histopathological changes, such as hyperplasia of follicular cells and related hypertrophic changes (Fig. 5A). In addition, MOK pharmacopuncture at 0.3 and $1.5 \mathrm{mg} / \mathrm{kg}$ significantly increased the follicular size $(\mathrm{P}<0.001$, respectively) compared with that of the control group (Fig. 5B). 
A

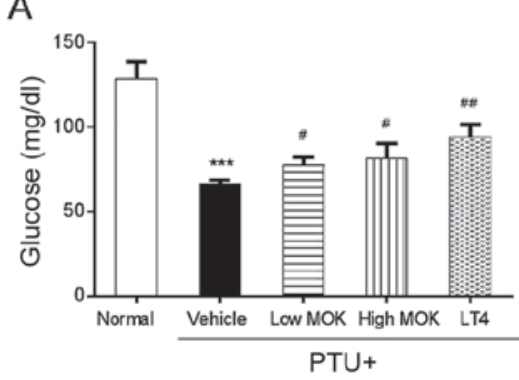

D

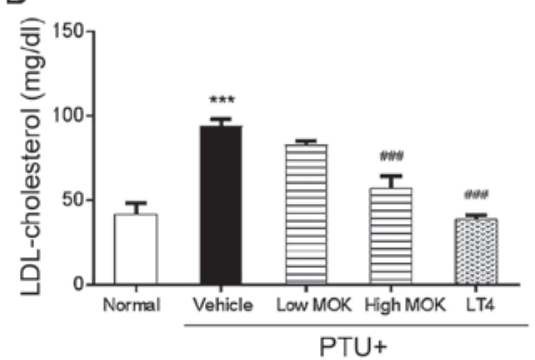

B

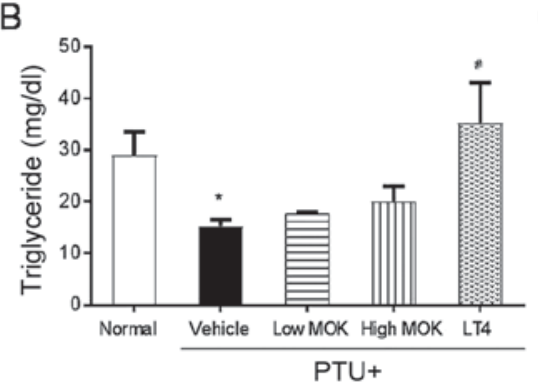

E

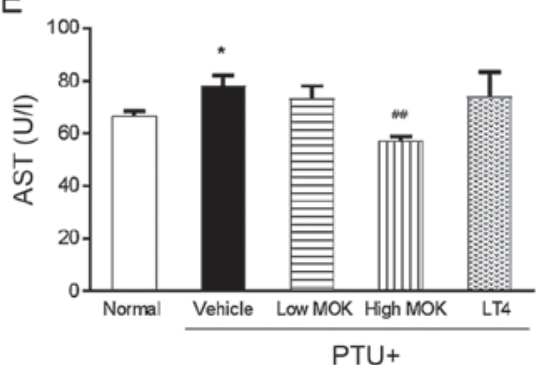

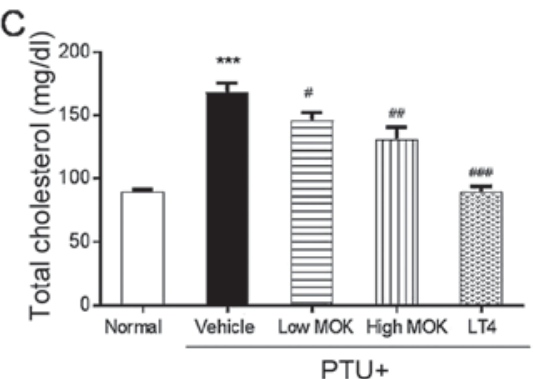

F

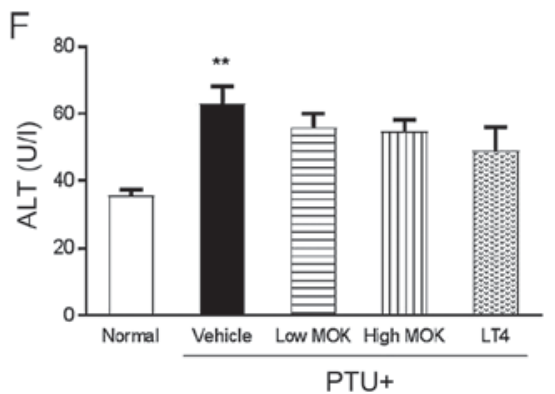

Figure 4. Effects of MOK pharmacopuncture on the changes of serological parameters in PTU-induced hyperthyroidism rats. MOK pharmacopuncture was subcutaneously administered once daily for 2 weeks, and the levels of (A) glucose, (B) triglyceride, (C) total cholesterol, (D) LDL-cholesterol, (E) AST, and (F) ALT in the sera of rats were measured by automatic blood biochemical analyzer. Data are presented as mean \pm standard deviation ( $=5$ per each group). ${ }^{*} \mathrm{P}<0.05,{ }^{* *} \mathrm{P}<0.01$, and ${ }^{* * *} \mathrm{P}<0.001$ vs. normal; ${ }^{\#} \mathrm{P}<0.05$, ${ }^{\# \#} \mathrm{P}<0.01$, and ${ }^{\# \# \#} \mathrm{P}<0.001$ vs. control. Normal, normal group; PTU+Vehicle, control group; PTU+Low MOK, MOK 0.3 ml/kg-treated group in control; PTU+High MOK, MOK $1.5 \mathrm{mg} / \mathrm{kg}$-treated group in control; and PTU+LT4, L-Thyroxine 0.5 mg/kg-treated group as a reference drug.
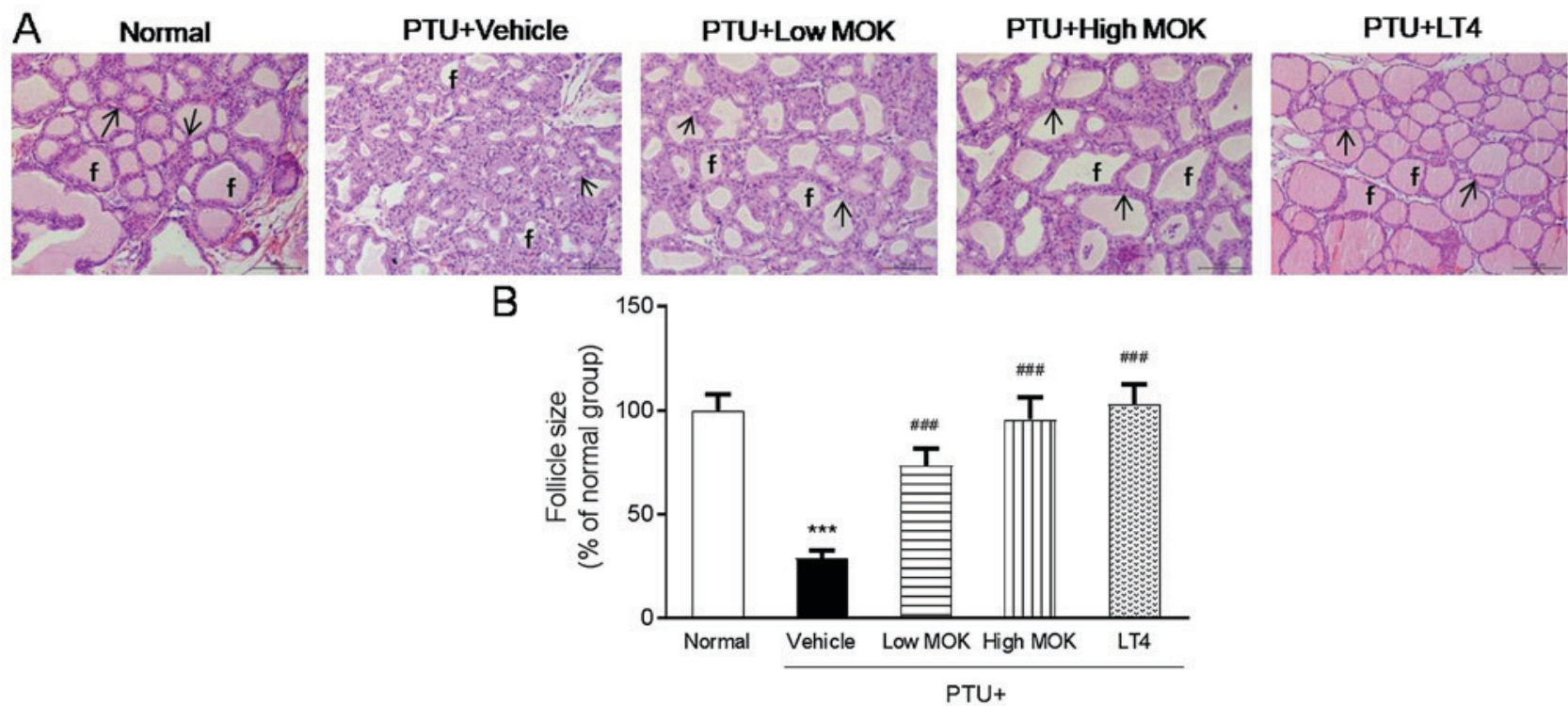

Figure 5. Effects of MOK pharmacopuncture on the histopathological changes of thyroid tissues in PTU-induced hypothyroidism rats. MOK pharmacopuncture was subcutaneously administered once daily for 2 weeks, and thyroid glands were isolated from the rats. (A) Thyroid tissues were stained with H\&E dye. Morphological changes were observed by a microscope at x200 in original magnification. Arrow: Follicle membrane, and f: Follicle. (B) The mean of relative follicular sizes to normal group were measured in PTU-induced hypothyroidism rats. Data are presented as mean \pm standard deviation ( $\mathrm{n}=5$ per each group). ${ }^{* * * *} \mathrm{P}<0.001$ vs. normal; ${ }^{\# \# \#} \mathrm{P}<0.001$ vs. control. Normal, normal group; PTU+Vehicle, control group; PTU+Low MOK, MOK $0.3 \mathrm{ml} / \mathrm{kg}$-treated group in control; PTU+High MOK, MOK $1.5 \mathrm{mg} / \mathrm{kg}$-treated group in control; and PTU+LT4, L-Thyroxine $0.5 \mathrm{mg} / \mathrm{kg}$-treated group as a reference drug.

Effect of MOK pharmacopuncture on oxidation in the liver and brain of hypothroidism rats. To investigate the effect of MOK pharmacopuncture on oxidative damage in hypothyroidism, we measured the levels of the antioxidant substance GSH in the liver tissues of hyperthyroidism rats and the expression of the antioxidant enzymes SOD and CAT in both liver and brain tissues. As shown in Fig. 6A, the level of
GSH was significantly $(\mathrm{P}<0.05)$ reduced in the liver tissues of PTU-induced hypothyroidism rats and significantly increased in the rats treated with $\mathrm{MOK}$ pharmacopuncture at 0.3 $(\mathrm{P}<0.01)$ and $1.5 \mathrm{mg} / \mathrm{kg}(\mathrm{P}<0.05)$. Next, the expression of SOD protein was increased in hypothyroidism rats and significantly decreased in both liver $(\mathrm{P}<0.05$; Fig. 6B) and brain tissues $(\mathrm{P}<0.01$; Fig. 6C) compared with that of the control group after 

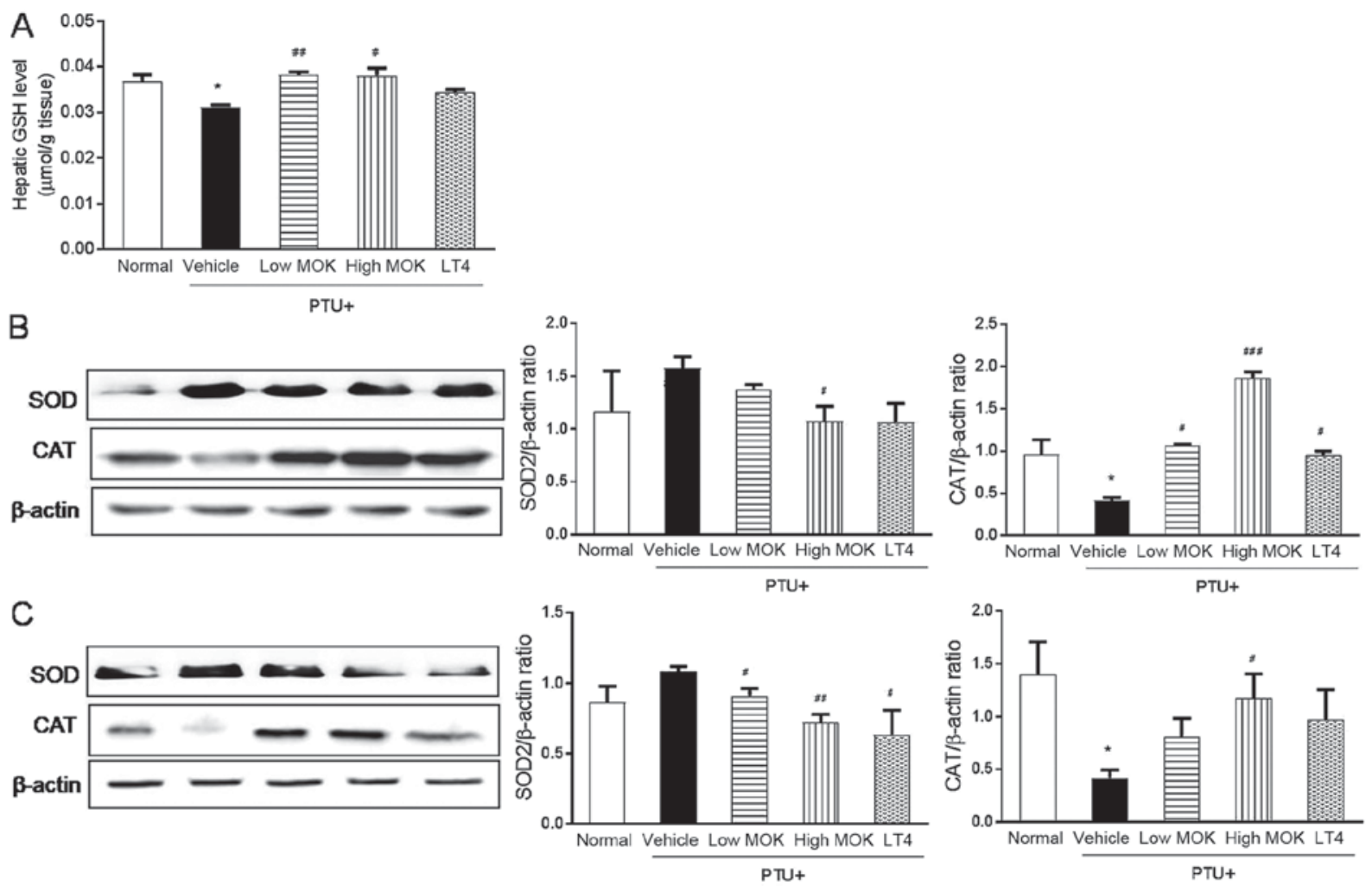

Figure 6. Effect of MOK pharmacopuncture on the oxidation in liver and brain tissues of PTU-induced hypothyroidism rats. MOK pharmacopuncture was subcutaneously administered once daily for 2 weeks, and the levels of (A) GSH from the liver of rats by ELISA were measured. The expression of CAT and SOD2 in the (B) liver and (C) brain tissues using western blot. Data are presented as mean \pm standard deviation ( $=5$ per each group). $\mathrm{P}<0.05$ vs. normal; ${ }^{\#} \mathrm{P}<0.05,{ }^{\# \#} \mathrm{P}<0.01$, and ${ }^{\# \# \#} \mathrm{P}<0.001$ vs. control. Normal, normal group; $\mathrm{PTU}+$ Vehicle, control group; PTU+Low MOK, MOK $0.3 \mathrm{ml} / \mathrm{kg}$-treated group in control; PTU+High MOK, MOK $1.5 \mathrm{mg} / \mathrm{kg}$-treated group in control; and PTU+LT4, L-Thyroxine $0.5 \mathrm{mg} / \mathrm{kg}$-treated group as a reference drug.

MOK pharmacopuncture at $1.5 \mathrm{mg} / \mathrm{kg}$. CAT expression was significantly $(\mathrm{P}<0.05)$ decreased in liver and brain tissues. The hypothyroidism-induced decrease in CAT was significantly increased in the liver $(\mathrm{P}<0.001)$ and brain tissues $(\mathrm{P}<0.05)$ by MOK pharmacopuncture at $1.5 \mathrm{mg} / \mathrm{kg}$.

Effect of MOK pharmacopuncture on body temperature and TRPV1 expression in hypothyroidism rats. To investigate the regulatory effect of body temperature in hypothyroidism, we measured the core body temperature, and the expression of the thermoregulator, TRPV1 channel in the DRG and brain tissues by western blot, respectively. In PTU-induced hypothyroidism rats, the body temperature from 2,3 , and 4 weeks after initial PTU treatment was significantly lower than the normal group $(\mathrm{P}<0.001)$ in a time-dependent manner (Fig. 7A). MOK pharmacopuncture at 0.3 and $1.5 \mathrm{mg} / \mathrm{kg}$ resulted in a significantly $(\mathrm{P}<0.01$, respectively) higher body temperature than that of the control group from 1 to 2 weeks after initial treatment. In the LT4-treated group, the body temperature was also significantly $(\mathrm{P}<0.001)$ higher than those of the PTU control group and normal rats. In LT-4-treated group, it was shown a significant increase of body temperature in hypothyroidism rats.

The expression of TRPV1 was significantly decreased in the DRG (Fig. 7B) by MOK pharmacopuncture at $0.3(\mathrm{P}<0.01)$ and $1.5 \mathrm{mg} / \mathrm{kg}(\mathrm{P}<0.05)$ and in the brain at $0.4 \mathrm{mg} / \mathrm{kg}(\mathrm{P}<0.01$, Fig. 7C) of hypothyroidism rats compared with the normal group. The treatment of LT4 also significantly decreased
TRPV1 expression in both DRG $(\mathrm{P}<0.01)$ and brain tissues $(\mathrm{P}<0.01)$.

Effects of MOK pharmacopunctureon the expression of IL-4, $I L-10$, Foxp3, and IFN- $\gamma$ in the spleen of hypothyroidism rats. To understand the action mechanism of MOK pharmacopuncture on Th1/Th2 immune response, we measured the serum levels of IFN- $\gamma$, Th1 cytokine, IL- 4 , and Th 2 cytokine in hypothyroidism rats by ELISA and the expression of IFN- $\gamma$, IL- 4 , IL-10, and Foxp3 mRNA in the spleen tissues by RT-PCR. Spleen weight was significantly $(\mathrm{P}<0.01)$ decreased in hypothyroidism rats compared with that of the normal group, and this decrease was significantly increased by MOK pharmacopuncture at $0.3(\mathrm{P}<0.01)$ and $1.5 \mathrm{mg} / \mathrm{kg}(\mathrm{P}<0.01)$ or LT4 treatment $(\mathrm{P}<0.05$; Fig. 8A). Next, MOK pharmacopuncture significantly decreased at $0.3(\mathrm{P}<0.01)$ and $1.5 \mathrm{mg} / \mathrm{kg}(\mathrm{P}<0.01)$ in the sera of hypothyroidism rats and significantly increased the IL-4 levels at $0.3(\mathrm{P}<0.01)$ and $1.5 \mathrm{mg} / \mathrm{kg}(\mathrm{P}<0.05)$. MOK pharmacopuncture decreased the expression of IFN- $\gamma$ mRNA, but increased the expression of IL-4 mRNA in the spleen tissues of hypothyroidism rats (Fig. 8C). Further, MOK pharmacopuncture significantly increased the expression of IL-10 and Foxp3 mRNA in the spleen tissues of hypothyroidism rats.

\section{Discussion}

Pharmacopuncture is a new form of acupuncture treatment in TKM; it is also known as acupoint injection in TCM, and 

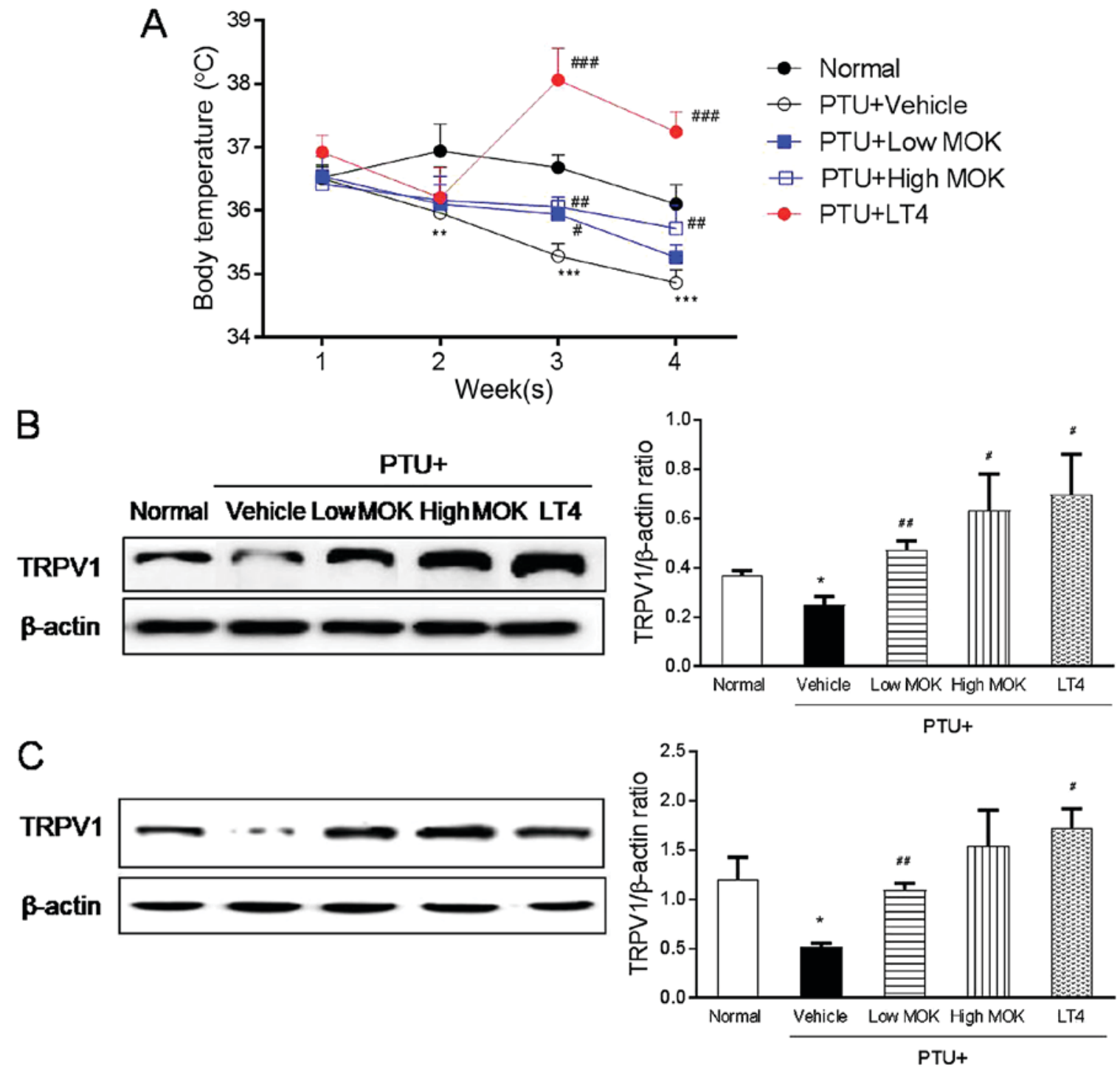

Figure 7. Effect of MOK pharmacopuncture on the changes in body temperature and the expression of TRPV1 protein in PTU-induced hypothyroidism rats. MOK pharmacopuncture was subcutaneously administered once daily for 2 weeks, and the body temperature was measured by (A) rectal thermometer once a week. The production of TRPV1 protein was determined in (B) DRG and (C) brain tissues isolated from PTU-induced hypothyroidism rats using western blot. Data are presented as mean \pm standard deviation ( $\mathrm{n}=5$ per each group). ${ }^{*} \mathrm{P}<0.05,{ }^{* * *} \mathrm{P}<0.01$, and ${ }^{* * *} \mathrm{P}<0.001$ vs. normal; ${ }^{*} \mathrm{P}<0.05$, ${ }^{\# \#} \mathrm{P}<0.01$, and

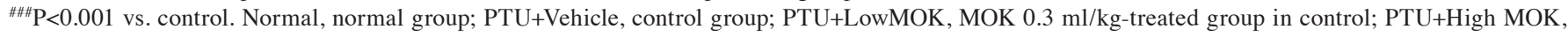
MOK $1.5 \mathrm{mg} / \mathrm{kg}$-treated group in control; and PTU+LT4, L-Thyroxine $0.5 \mathrm{mg} / \mathrm{kg}$-treated group as a reference drug.

it has better efficacy than oral administration because the drug does not pass through the digestive system. Therefore, pharmacopuncture is commonly applied in Korean clinics. This method has often been used for the regulation of immune imbalance in TKM. MOK is a polyherbal medicine for immuno-pharmacopuncture, and MOK pharmacopuncture is used to treat patients with thyroid diseases such hyperthyroidism and hypothyroidism. It is believed that MOK pharmacopuncture has a good effect on immune regulation in thyroid diseases, but its scientific evidence has been little studied. In our previous study, we found that MOK showed an anti-inflammatory effect in LPS-stimulated macrophages (8) and a modulatory effect on Th1/Th2 immune response in ConA-stimulated splenocytes (9). In the present study, we confirmed the therapeutic effect of MOK pharmacopuncture on PTU-induced hypothyroidism in rats through regulation of the imbalance of thyroid hormones, body temperature, and antioxidation. MOK pharmacopuncture is clinically applied with MOK extract at 0.3 to $0.8 \mathrm{mg} / \mathrm{ml}$ in acupoints of thyroid region of the patients ( $45 \mathrm{~kg} \mathrm{BW}$ ) twice a week for 3 months according to the guideline of KIPA. In this study, we used MOK extract at 0.3 and $1.5 \mathrm{mg} / \mathrm{ml}$ in rats once a day for 2 weeks after induction of hypothyroidism.

Because thyroid hormones are known to play a fundamental role in the regulation of various types of metabolism in the body, their insufficient release can induce hypothyroidism with inhibition of basic body metabolism, decrease in catabolic actions, accumulation of tissue glycoproteins, and increase in BW $(3,14)$. In our study, hypothyroidism was induced in rats by injection of the PTU as a representative inhibitor of thyroid functions (11-13). It has been reported that PTU-induced hypothyroidism rats showed absolute reduction of T3 and T4 levels and the increase in TSH, similar to human hypothyroidism $(11,15)$. Therefore, laboratory evaluation of 
A

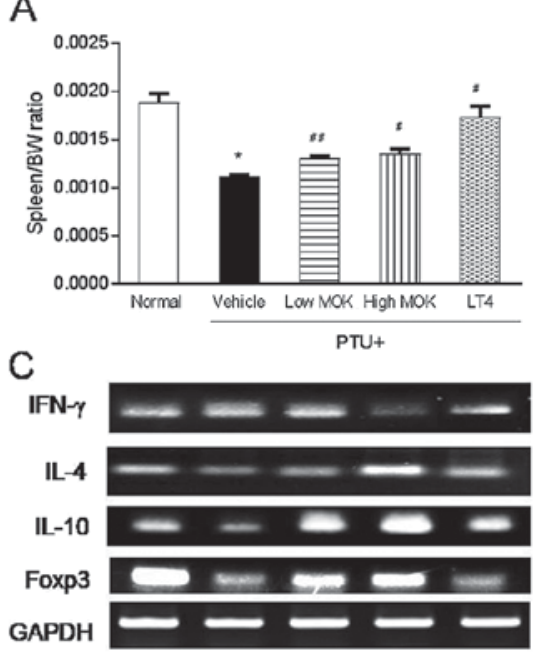

B
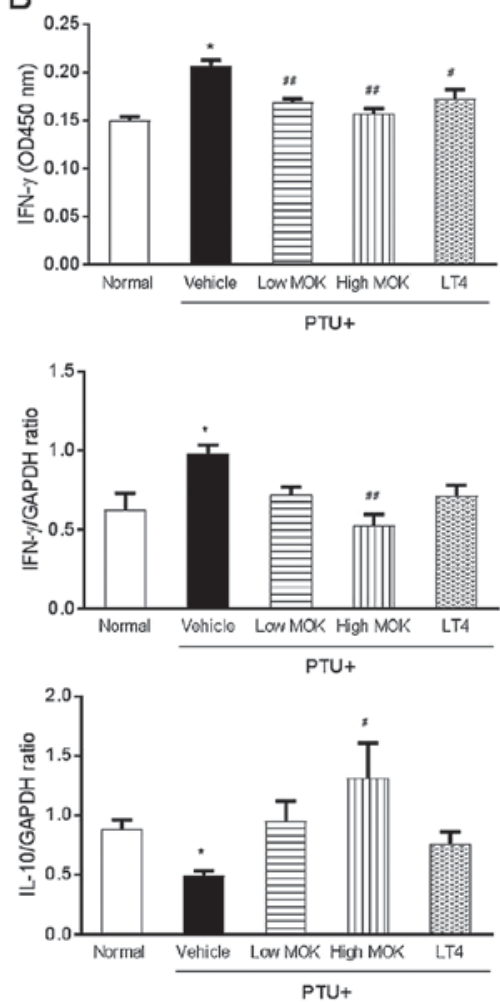
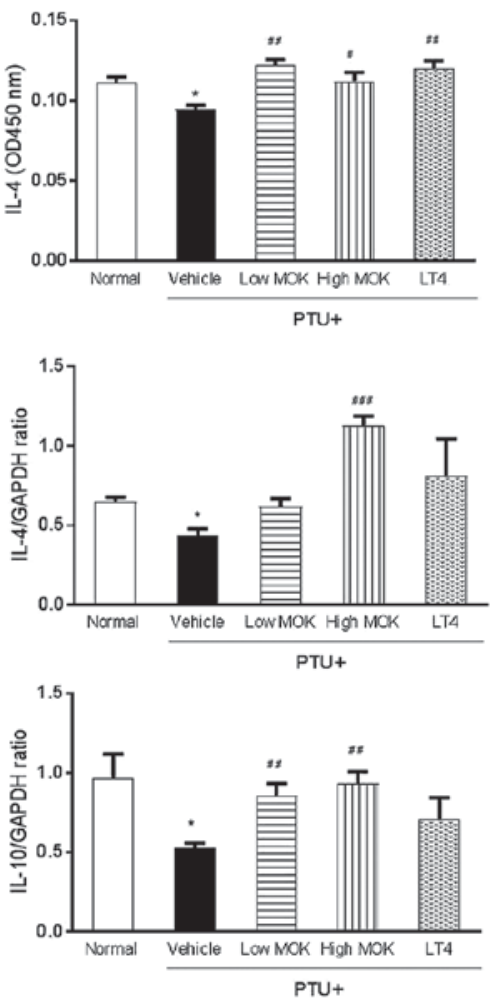

Figure 8. Effects of MOK pharmacopuncture on the expression of IL-4, IL-10, Foxp3, and IFN- $\gamma$ in the spleen of PTU-induced hypothyroidism rats. MOK pharmacopuncture was subcutaneously administered once daily for 2 weeks, and the weight of the spleen (A) in PTU-induced hypothyroidism rats was measured. Relative organ weights to body weights were measured. (B) The serum levels of IFN- $\gamma$ and IL-4 in hypothyroidism rats by ELISA and (C) the expression of IFN- $\gamma$, IL-4, IL-10, and Foxp3 mRNA in the spleen tissues by RT-PCR, respectively. Data are presented as mean \pm standard deviation ( $=5$ per each group). ${ }^{*} \mathrm{P}<0.05$ vs. normal; ${ }^{\#} \mathrm{P}<0.05,{ }^{\# \#} \mathrm{P}<0.01$, and ${ }^{\# \# \#} \mathrm{P}<0.001$ vs. control. Normal, normal group; PTU+Vehicle, control group; $\mathrm{PTU}+\mathrm{Low} \mathrm{MOK}, \mathrm{MOK}$ $0.3 \mathrm{ml} / \mathrm{kg}$-treated group in control; PTU+High MOK, MOK $1.5 \mathrm{mg} / \mathrm{kg}$-treated group in control; and PTU+LT4, L-Thyroxine 0.5 mg/kg-treated group as a reference drug.

TSH, T3, and T4 levels is considered the best screening test for hypothyroidism (16). We also found marked and noticeable increase in TSH and decrease in T3 and T4 levels in PTU-induced hypothyroidism rats.

Patients with diabetes and hyperglycemia have a higher prevalence of thyroid disorders than the normal population (17). Hypothyroidism is also accompanied by a variety of abnormalities in plasma lipid metabolism, including elevated TG and LDL cholesterol concentrations (18). In our study, PTU-induced hypothyroidism rats showed a significant decrease in serum glucose and TG levels, but a significant increase in serum total cholesterol, LDL-cholesterol, AST and ALT levels. MOK pharmacopuncture in hypothyroidism rats increased glucose levels and decreased lipid accumulation in both low and high doses, suggesting that MOK pharmacopuncture can regulate the hypothyroidism-induced metabolism abnormality similar to LT4 treatment. Thyroid hormones were found to affect lipid concentration, hepatic metabolism, and the synthesis of cholesterol $(17,18)$. The abnormalities of lipoprotein metabolism commonly involved with hypothyroidism are elevated levels of total cholesterol and LDL-cholesterol. Elevated cholesterols can induce the development of lethal cardiovascular diseases as side effects of hypothyroidism $(18,19)$. These abnormal blood lipid levels in hypothyroidism are ameliorated by LT4 treatment $(17,20,21)$. In our study, MOK pharmacopuncture significantly decreased the levels of total cholesterol and LDL-cholesterol in both low and high doses. These results suggest that MOK pharmacopuncture can reduce the risk of diabetes and cardiovascular diseases through the regulation of lipid accumulation similar to LT4 treatment.

The liver is the main target organ of thyroid hormone; therefore, hypothyroidism is commonly accompanied with hepatic damage (22). Thyroid hormones are known to play an essential role in hepatocyte proliferation of rat liver (23). Its serious damage was accompanied to the thyroid hormones imbalances regardless of hypothyroidism. Clinical diagnosis of disease and damage to the structural integrity of liver is also commonly assessed by monitoring the status of serum AST and ALT activities (24). In our study, PTU treatment significantly increased serum levels of AST and ALT, and they were significantly inhibited by L-thyroxin and MOK pharmacopuncture in both low and high concentrations.

In general, hypothyroidism is accompanied by a decrease in the basic body metabolism, and internal respiration. In return, it induces inhibition of lipid peroxidation and weak increase in the endogenous antioxidant enzymes such as SOD and CAT against the release of harmful reactive oxygen species (ROS) and hydrogen peroxide $\left(\mathrm{H}_{2} \mathrm{O}_{2}\right)$ in hepatic tissue. Recently, several trials have been conducted to determine the potent and less toxic natural origin antioxidants for use in hypothyroidism treatment (25-27). In our study, MOK pharmacopuncture 
significantly decreased the GSH content and CAT activity and slightly increased SOD activity in the liver and brain tissues of hypothyroidism rats similar to LT4 treatment. These results indicate that MOK pharmacopuncture can protect liver and brain tissues against hypothyroidism-induced oxidative stress.

In this study, we also found that MOK pharmacopuncture regulated body temperature in hypothyroidism rats through inhibition of the thermoregulator TRPV1 channel. Higher rectal temperature has been found to be induced in LT4-induced hyperthyroidism rats (28), while lower temperature is found in PTU-induced hypothyroidism rats (15). In our study, a decrease in body temperature was observed in PTU-induced hypothyroidism rats, and that was increased by MOK pharmacopuncture. Our sensory nerves use specialized ion channel proteins to report environmental temperatures, most notably, but not exclusively, TRP ion channels (29-31). TRPV1 channels in sensory nerves respond to heat and to capsaicin, an alkaloid from 'hot' peppers, which binds to open the channel and thus depolarizes the neuron and fires action potentials (32). Drugs that block TRPV1 input to the brain provoke hypothalamic-mediated changes in metabolism that elevate body temperature $(33,34)$. It is also known that the DRG neurons in rats are sensitive to capsaicin $(34,35)$. In our study, the regulation of body temperature by MOK pharmacopuncture was linked to the regulation of TRPV1 in DRG and brain tissues. These results suggest that MOK pharmacopuncture can regulate the change in body temperature through the regulation of the thermo-regulating protein TRPV1 on hypothyroidism similar to LT4 treatment.

In the body, the spleen is an important immune organ, and splenocytes consist of different white blood cell types such as T and B lymphocytes, dendritic cells, and macrophages, which have different immune functions $(36,37)$. Thus, in the drug efficacy study, the immune modulatory evaluation of splenocytes provides an understanding of the influence on $\mathrm{T}$ and B cells (36). In our study, we also evaluated the immune modulatory effects of MOK pharmacopuncture, wherein the changes of Th1/Th2 cytokines were investigated in the splenocytes of hypothyroidism rats. Th cytokines from the CD4+ Th lymphocytes are thought to regulate the function of the immune system, including antibody production and cellular immune response (38). Th cells represent a functionally heterogeneous population, comprising distinct subsets termed Th1 and Th2 defined by their cytokine secretion profiles (39). Th1 cells secrete Th1 cytokines such as IL-2, IFN- $\gamma$, IL-12 and TNF- $\alpha$, while Th 2 cells secrete Th 2 cytokines, such as IL-4, IL-10, and Foxp3. The communication network between Th1 and Th2 cytokines may be synergistic or antagonistic toward lymphocyte proliferation and differentiation $(40,41)$. In our study, MOK pharmacopuncture significantly decreased the levels of IFN- $\gamma$ as a main Th1 cytokine and increased the levels of IL-4 as a main Th2 cytokine in the spleen of PTU-induced hypothyroidism rats. The increase in Th1 cytokine and the decrease in Th2 cytokines have been reported in hypothyroidism (42). Therefore, our finding indicates that MOK pharmacopuncture has an immune modulatory property on imbalance of Th1/Th2, which has been found to reduce the disease severity of hypothyroidism.
Natural regulatory $\mathrm{T}$ (Treg) cells are constitutively produced in the thymus; they express very high levels of CD25 and produce IL-10 with the expression of Foxp3 (43-45). The role of CD4+CD25+FoxP3+ Treg cells has been widely reported in the prevention of autoimmune diseases and immunopathology in all types of infections $(46,47)$. In our study, MOK pharmacopuncture significantly increased the expression of IL-10 and FoxP3 mRNA in the spleen of PTU-induced hypothyroidism rats. MOK pharmacopuncture also regulated the imbalance of Th1/Th2 cytokines at high dose, however, further study is needed, suggesting that MOK pharmacopuncture can help to suppress autoimmune response. Some data suggest that the transcription factors such as interferon regulatory factors (IFRs) are involved in the pathogenesis of many autoimmune disorders (48). IRF7have been implicated in metabolic autoimmune disorders including diabetes and obesity (49). However, the systemic effects of IRFs on metabolism are largely unknown. In further study, we will investigate the effects of MOK pharmacopuncture on hypothyroidism by the metabolic regulation of IRFs, which suggests a new strategy for treatment of thyroid autoimmune diseases.

In this study, we firstly demonstrated that MOK pharmacopuncture has a therapeutic effect on hypothyroidism rats, suggesting that MOK pharmacopuncture can make a good use for the treatment of hypothyroidism patients. However, the mechanism of responsible for the therapeutic effects of MOK and the function of MOK constituents require further research. In our study, small groups ( $\mathrm{n}=5$ in each group) with approval of IACUC were used, however, it will be added the numbers of animals for better understanding of MOK pharmacopuncture for further study.

In conclusions, MOK pharmacopunture in PTU-induced hypothyroidism rats was found to improve the pathological progression by normalization of the hypothyroidism-induced thyroid hormone imbalance, inhibition of lipid accumulation, and antioxidation, similar to L-thyroxin. The underlying mechanism was related to the regulation of body temperature by TRPV1 channel activation and Th1/Th2 cytokine imbalance. This indicates that MOK pharmacopuncture is a useful therapy for patients with hypothyroidism in traditional clinics.

\section{Acknowledgements}

This study was supported by the National Research Foundation of Korea (NRF) grant funded by the Korea government [Ministry of Science, ICT and Future Planning (MSIP); grand no. NRF-2017R1C1B5076224].

\section{Competing interests}

The authors declare that they have no competing interests.

\section{References}

1. Gaberšček S and Zaletel K: Thyroid physiology and autoimmunity in pregnancy and after delivery. Expert Rev Clin Immunol 7: 697-706, 2011.

2. Chakera AJ, Pearce SH and Vaidya B: Treatment for primary hypothyroidism: Current approaches and future possibilities. Drug Des Devel Ther 6: 1-11, 2012. 
3. Garber JR, Cobin RH, Gharib H, Hennessey JV, Klein I, Mechanick JI, Pessah-Pollack R, Singer PA and Woeber KA; American Association Of Clinical Endocrinologists And American Thyroid Association Taskforce On Hypothyroidism In Adults: Clinical practice guidelines for hypothyroidism in adults: Cosponsored by the American Association of Clinical Endocrinologists and the American Thyroid Association. Thyroid 22: 1200-1235, 2012.

4. Korean Acupuncture and Moxibustion Medicine Society: Pharmacopuncture therapy. In: Acupuncture Medicine Kim JH (ed) Hanmi Medical Publishing co., Paju, pp204-208, 2016 (In Korean).

5. Jung C, Jung JH and Lee MS: Pharmacopuncturemedines. In: A clinical study of immune pharmacopuncturology. Jung C (ed) Kyungrak Medical Publishing Co., Chungnam, pp127-133, 2011 (In Korean).

6. Hwang JH: A case report of Hwa-byeong with MOK Herbal acupuncture therapy. J Immuno-Pharmacopuncture 2: 43-55, 2013 (In Korean).

7. Kim HJ, Gwan R, Han JW, Jung C and Park KH: Analysis of physioactivities on MOK yakchim. J Immuno-Pharmacopuncture 2: 17-25, 2013 (In Korean).

8. Hwang JH, Hwang MS and Park YK: MOK, a pharmacopuncture medicine, reduces inflammatory response through inhibiting the proinflammatory cytokine production in LPS-stimulated mouse peritoneal macrophages. Acupuncture 34: 11-21, 2017.

9. Hwang JH: Effects of MOK, a pharmacopuncture medicine, on the TH1/TH2 immune response and antioxidation in Con A-stimulated primary mouse splenocytes. Acupuncture 34: 39-48, 2017.

10. Somers SL: Examining anger in 'culture-bound' syndromes. Psychiatric Times 15, 1998.

11. Ashwini S, Bobby Z, Sridhar MG and Cleetus CC: Insulin plant (costus pictus) extract restores thyroid hormone levels in experimental hypothyroidism. Pharmacognosy Res 9: 51-59, 2017.

12. Choudhuryl S, Chainyl GB and Mishro MM: Experimentally induced hypo- and hyper-thyroidism influence on the antioxidant defence system in adult rat testis. Andrologia 35: 131-140, 2003.

13. Rooney AA, Matulka RA and Luebke RW: Developmental atrazine exposure suppresses immune function in male, but not female Sprague-Dawley rats. Toxicol Sci 76: 366-375, 2003.

14. Zamoner A, Barreto KP, Filho DW, Sell F, Woehl VM, Guma FC Pessoa-Pureur R and Silva FR: Propylthiouracil-induced congenital hypothyroidism upregulates vimentin phosphorylation and depletes antioxidant defenses in immature rat testis. J Mol Endocrinol 40: 125-135, 2008.

15. Subudhi U, Das K, Paital B, Bhanja S and Chainy GB: Supplementation of curcumin and vitamin $\mathrm{E}$ enhances oxidative stress, but restores hepatic histoarchitecture in hypothyroid rats. Life Sci 84: 372-379, 2009.

16. Brown RS: Autoimmune thyroiditis in childhood. J Clin Res Pediatr Endocrinol 5 (Suppl 1): S45-S49, 2013.

17. Patricia Wu: Thyroid disease and diabetes. Clin Diabetes Winter 18 : 38, 2000.

18. Mullur R, Liu YY and Brent GA: Thyroid hormone regulation of metabolism. Physiol Rev 94: 355-382, 2014.

19. Rizos CV, Elisaf MS and Liberopoulos EN: Effects of thyroid dysfunction on lipid profile. Open Cardiovasc Med J 5: 76-84, 2011

20. Ito M, Arishima T, Kudo T, Nishihara E, Ohye H, Kubota S, Fukata S, Amino N, Kuma K, Sasaki I, et al: Effect of levo-thyroxine replacement on non-high-density lipoprotein cholesterol in hypothyroid patients. J Clin Endocrinol Metab 92: 608-611, 2007.

21. Teixeira Pde F, Reuters VS, Ferreira MM, Almeida CP, Reis FA, Buescu A, Costa AJ and Vaisman M: Lipid profile in different degrees of hypothyroidism and effects of levothyroxine replacement in mild thyroid failure. Transl Res 151: 224-231, 2008.

22. Simon-Giavarotti KA, Giavarotti L, Gomes LF, Lima AF, Veridiano AM, Garcia EA, Mora OA, Fernández V, Videla LA and Junqueira VB: Enhancement of lindane-induced liver oxidative stress and hepatotoxicity by thyroid hormone is reduced by gadolinium chloride. Free Radic Res 36: 1033-1039, 2002.

23. Torres S, Díaz BP, Cabrera JJ, Díaz-Chico JC, Díaz-Chico BN and López-Guerra A: Thyroid hormone regulation of rat hepatocyte proliferation and polyploidization. Am J Physiol 276: G155-G163, 1999.

24. Amin A and Hamza AA: Oxidative stress mediates drug-induced hepatotoxicity in rats: A possible role of DNA fragmentation. Toxicology 208: 367-375, 2005 .
25. Bhanja S and Chainy GB: PTU-induced hypothyroidism modulates antioxidant defence status in the developing cerebellum. Int J Dev Neurosci 28: 251-262, 2010.

26. Messarah M, Saoudi M, Boumendjel A, Boulakoud MS and Feki AE: Oxidative stress induced by thyroid dysfunction in rat erythrocytes and heart. Environ Toxicol Pharmacol 31: 33-41, 2011.

27. Das K and Chainy GB: Modulation of rat liver mitochondrial antioxidant defence system by thyroid hormone. Biochim Biophys Acta 1537: 1-13, 2001.

28. Subudhi U, Das K, Paital B, Bhanja S and Chainy GB: Alleviation of enhanced oxidative stress and oxygen consumption of L-thyroxine induced hyperthyroid rat liver mitochondria by vitamin $\mathrm{E}$ and curcumin. Chem Biol Interact 173: 105-114, 2008.

29. Ramsey IS, Delling M and Clapham DE: An introduction to TRP channels. Annu Rev Physiol 68: 619-647, 2006.

30. Nilius B, Owsianik G, Voets T and Peters JA: Transient receptor potential cation channels in disease. Physiol Rev 87: 165-217, 2007.

31. Wu LJ, Sweet TB and Clapham DE: International Union of Basic and Clinical Pharmacology. LXXVI. Current progress in the mammalian TRP ion channel family. Pharmacol Rev 62: 381-404, 2010.

32. Caterina MJ, Rosen TA, Tominaga M, Brake AJ and Julius D: A capsaicin-receptor homologue with a high threshold for noxious heat. Nature 398: 436-441, 1999.

33. Gavva NR, Treanor JJ, Garami A, Fang L, Surapaneni S, Akrami A, Alvarez F, Bak A, Darling M, Gore A, et al: Pharmacological blockade of the vanilloid receptor TRPV1 elicits marked hyperthermia in humans. Pain 136: 202-210, 2008.

34. Wang $\mathrm{H}$ and Siemens J: TRP ion channels in thermosensation, thermoregulation and metabolism. Temperature (Austin) 2: 178-187, 2015.

35. Liu PW, Blair NT and Bean BP: Action potential broadening in capsaicin-sensitive DRG neurons from frequency-dependent reduction of Kv3 current. J Neurosci 37: 9705-9714, 2017.

36. Cesta MF: Normal structure, function, and histology of the spleen. Toxicol Pathol 34: 455-465, 2006

37. Bronte V and Mikael MJ: The spleen in local and systemic regulation of immunity. Immunity 39: 806-818, 2013.

38. Kaiko GE,Horvat JC, Beagley KW and Hansbro PM: Immunological decision-making: How does the immune system decide to mount a helper T-cell response?. Immunology 123: 326-338, 2008.

39. Romagnani S: Biology of human TH1 and TH2 cells. J Clin Immunol 15: 121-129, 1995.

40. Murphy KM and Reiner SL: The lineage decisions of helper T cells. Nat Rev Immunol 2: 933-944, 2002

41. Abbas AK, Murphy KM and Sher A: Functional diversity of helper T lymphocytes. Nature 383: 787-793, 1996.

42. Ganesh BB, Bhattacharya P, Gopisetty A and Prabhakar BS: Role of cytokines in the pathogenesis and suppression of thyroid autoimmunity. J Interferon Cytokine Res 31: 721-731, 2011.

43. Barthlott T, Moncrieffe H, Veldhoen M, Atkins CJ, Christensen J, O'Garra A and Stockinger B: CD25+ CD4+ T cells compete with naive CD4+ T cells for IL-2 and exploit it for the induction of IL-10 production. Int Immunol 17: 279-288, 2005.

44. Setoguchi R, Hori S, Takahashi T and Sakaguchi S: Homeostatic maintenance of natural Foxp3(+) CD25(+) CD4(+) regulatory T cells by interleukin (IL)-2 and induction of autoimmune disease by IL-2 neutralization. J Exp Med 201: 723-735, 2005.

45. Wan YY and Flavell RA: Regulatory T-cell functions are subverted and converted owing to attenuated Foxp3 expression. Nature 445: 766-770, 2007.

46. Sakaguchi S: Naturally arising Foxp3-expressing CD25+CD4+ regulatory $\mathrm{T}$ cells in immunological tolerance to self and non-self. Nat Immunol 6: 345-352, 2005.

47. Belkaid Y: Regulatory T cells and infection: A dangerous necessity. Nat Rev Immunol 7: 875-888, 2007.

48. Richez C, Barnetche T, Miceli-Rechard C, Blanco P, Moreau JF, Rifkin I and Scharverbeke T: Role for interferon regulatory factors in autoimmunity. Joint Bone Spine 77: 525-531, 2010.

49. Wang XA, Zhang R, Zhang S, Deng S, Jiang D, Zhong J, Yang J, Wang T, Hong S, Guo S, et al: Interferon regulatory factor 7 deficiency prevents diet-induced obesity and insulin resistance. Am J Physiol Endocrinol Metab 305: E485-E495, 2013.

This work is licensed under a Creative Commons Attribution-NonCommercial-NoDerivatives 4.0 International (CC BY-NC-ND 4.0) License. 